\title{
Formação do professor de História nos contextos alemão e brasileiro: algumas questões sobre a relação entre teoria e prática
}

German and Brazilian contexts in history teacher training: some questions regarding theory and practice

Rosiane Ribeiro Bechler*

Cristiani Bereta da Silva**

Resumo

$\mathrm{O}$ artigo pretende estabelecer um diálogo entre a formação docente em História no Brasil, tendo como parâmetro o Curso de História da Universidade do Estado de Santa Catarina (Udesc) - destacando o lugar das práticas e do estágio nesse processo - e a formação docente em História na Alemanha, realizada em duas etapas - uma de estudos acadêmicos, mas já com inserções no contexto escolar, e outra prática, compreendida como preparo para o início efetivo do trabalho. A discussão assentou-se em experiências vivenciadas nos dois países, na bibliografia e nos documentos disponíveis nos sites do Ministério Bávaro para Formação e Educação, Ciência e Cultura e da Universidade Julius-Maximilian/Würzburg e,

\section{Abstract}

The main focus of this article is to establish a dialogue between teacher training in history in Brazil, having as parameter the History Course at the University of the State of Santa Catarina (Udesc) highlighting the place of practice and internship in this process - as well as teacher training History in Germany, held in two stages - a scholarship one but already with inserts in the school's context, and a practical one, understood as a preparation for the start. This discussion was based on life experiences in both countries, in the literature and documents available on the Ministry Bavarian site for Training and Education, Science and Culture and the site of the JuliusMaximilian University/Würzburg and also on the perceptions shared by a

\footnotetext{
* Professora Substituta do Centro de Ciências da Educação da Universidade Federal de Santa Catarina (UFSC), atua nas disciplinas de Estágio Supervisionado para licenciatura em História. Doutoranda em Educação na Universidade do Estado de Santa Catarina (Udesc). Bolsista da Capes.rosiribeirobechler@gmail.com

** Professora do Departamento de História e dos Programas de Pós-Graduação em História, em Educação e Mestrado Profissional em Ensino de História da Universidade do Estado de Santa Catarina (Udesc). Bolsista produtividade em pesquisa do CNPq. cristianibereta@gmail.com
} 
ainda, nas percepções partilhadas por uma professora em fase final de formação nessa instituição. Defende-se, aqui, uma formação inicial pautada no diálogo contínuo entre teoria e prática, reconhecendo que o ensino também é campo de elaboração e consolidação de saberes. Palavras-chave: formação de professores; estágio supervisionado; História.
Professor in the final phase of training at the same institution. We believe and endorse the capability of an initial training guided by the ongoing dialogue between theory and practice, recognizing that education is also a field for the developing and the consolidation of knowledge. Keywords: teacher training; supervised teaching practice; history.

Nos últimos 30 anos a formação docente tem sido objeto privilegiado de reformas, tanto no cenário nacional quanto no internacional. Nesse movimento a maioria dos países enfrentou transformações que afetaram diferentes dimensões dessa formação, tais como: organização curricular, o espaço institucional onde a formação deve ocorrer, sistemas de avaliação, financiamento, competências para o exercício da função etc. Tais embates políticos e novas compreensões sobre o espaço escolar, saberes escolares, e especialmente saberes docentes, fundamentam a definição de um outro lugar para as práticas de ensino e estágios supervisionados no currículo da formação inicial dos docentes de História.

Compartilhamos da ideia de que a formação profissional docente é por natureza inacabada, e, portanto, contínua (Freire, 2014). Nesse sentido, o tempo e as experiências partilhadas na formação inicial são um dos aspectos desse processo, ampliado e intensificado no embate com as vivências do cotidiano escolar e demandas impostas pelo tempo presente. Mas também acreditamos na potencialidade de uma formação inicial pautada no diálogo contínuo entre teoria e prática, reconhecendo que o ensino é campo de elaboração e consolidação de saberes. Essa concepção demanda de professores e professorandos envolvidos no percurso de formação uma postura de comprometimento e reflexão nesse e sobre esse lugar de fronteira (Monteiro, 2007) que é o ensino de História, no intuito de promover, por um lado, a compreensão das especificidades da História como saber escolar e, por outro, a apreensão do contexto escolar como campo profissional para atuação docente.

Nesse percurso acreditamos na potencialidade de conhecer e problematizar experiências outras, que possam agregar às nossas reflexões possibilidades até então desconsideradas ou pouco problematizadas. Por isso, estabelecemos 
neste artigo um diálogo entre a formação docente em História no Brasil, tendo como parâmetro o Curso de História da Universidade do Estado de Santa Catarina (Udesc) - destacando o lugar das práticas e do estágio nesse processo - e a formação docente em História na Alemanha, realizada em duas etapas uma de estudos acadêmicos, mas já com inserções no contexto escolar, e outra prática, compreendida como preparo para o início efetivo do trabalho.

Alguns autores (Ceballos, 1995; Fichtner; Benites, 2005; Goergen, 1998) já se dedicaram à análise do sistema de ensino na Alemanha, conhecido por sua complexidade e organicidade. Importante lembrar que a configuração desse sistema de ensino evidencia as marcas de um país que, além de possuir uma complexa organização federativa descentralizada, experienciou duas guerras mundiais e profundas transformações socioeconômicas com recentes rupturas, como a queda do Muro de Berlim. Por ser um tema denso, que demandaria um artigo específico para sua discussão, iremos nos limitar aqui a apresentar um panorama geral desse sistema, indispensável à compreensão das características próprias da formação docente na Alemanha, e em específico na Bavária. Destacamos isso porque na República Federal Alemã os estados têm autonomia em matéria de educação e cultura garantida pela Constituição Federal. Contudo, isso não significa que o sistema seja totalmente descentralizado. Para Pedro Goergen (1998, p.18) o governo federal descentraliza, mas os estados, cada qual a seu modo, mantêm sistemas rigidamente centralizados em todos os níveis de ensino (à exceção das universidades que têm maior autonomia), com limitada participação dos municípios e escolas. Sobre a organização do sistema de ensino, observa-se também que o currículo em todos os níveis de ensino é de responsabilidade da Federação, a formação e os concursos de todos os professores são de responsabilidade do governo estadual, e a administração das escolas é de responsabilidade dos municípios (Fichtner; Benites, 2005, p.538).

As reflexões que aqui apresentamos referem-se especificamente ao estado da Bavária, localizado ao sul da Alemanha. Baseamo-nos em experiências vivenciadas nesse país, ${ }^{1}$ na bibliografia disponível, nos documentos disponíveis nos sites do Ministério Bávaro para Formação e Educação, Ciência e Cultura ${ }^{2}$ e da Universidade Julius-Maximilian/Würzburg, ${ }^{3}$ e ainda nas percepções partilhadas por uma professora em fase final de formação nessa mesma instituição, Viktoria Freifrau von Wiedersperg. 
O sistema de ensino na Alemanha é essencialmente público, do jardim de infância à Universidade. O número de escolas privadas é insignificante em comparação com as públicas, e elas necessitam reconhecimento estatal para desenvolverem suas atividades. O sistema de ensino preponderante no país, denominado dual, oferece mais de uma possibilidade de formação e requer professores aptos para lecionar conforme as especificidades de cada segmento (ver Gráfico 1).

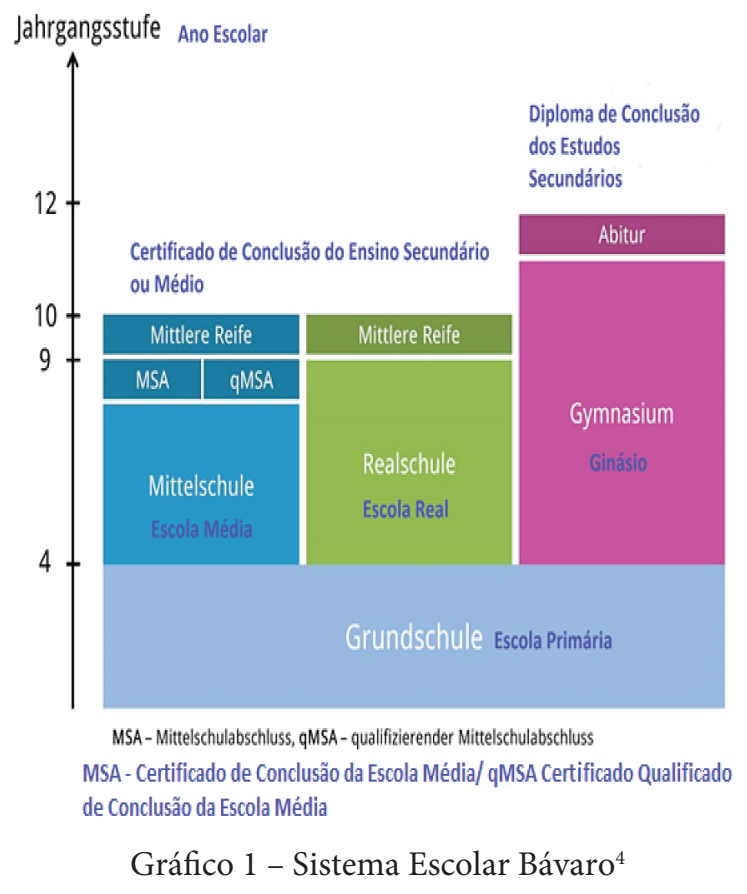

A estrutura representada refere-se ao sistema regular de escolarização ${ }^{5}$ no qual as crianças ingressam aos 6 anos de idade, e em livre tradução podem ser assim correlacionadas à realidade brasileira: a Grundschule seria uma escola primária, da $1^{\text {a a }} 4^{\text {a }}$ série, na qual “todos” iniciam sua vida escolar. Passada essa primeira etapa, conforme a avaliação dos professores em diálogo com os pais e as notas obtidas, as crianças são orientadas a seguir por um dos três caminhos possíveis para formação secundária, escolha essa que vai incidir no próprio futuro profissional da criança. $\mathrm{O}$ primeiro deles refere-se à continuidade de 
estudos na Mittelschule ou Hauptschule, ou Escola Média, que oferece a preparação considerada como básica e indispensável à formação escolar; após concluir essa etapa, com duração de 5 a 6 anos, e serem aprovados no exame final para certificação de conclusão do ensino secundário, ${ }^{6}$ os alunos podem se inscrever em Escolas Profissionalizantes, cujas especificidades não serão aqui abordadas. Outra possibilidade é a realização da formação secundária na Realschule, ou Escola Real, com duração prevista de 6 anos, na qual os alunos além da formação escolar básica são preparados para ingressar em Cursos Técnicos ${ }^{7}$ e, para tanto, já recebem uma formação profissionalizante inicial em parceria com empresas e fábricas interessadas em mão de obra qualificada e especializada. A terceira possibilidade, no sistema de ensino dual e regular, seriam os estudos no Gymnasium, ou Ginásio, com duração de 8 anos e voltados especialmente para o preparo de estudantes que irão ingressar na Universidade. Estes precisam estar de posse de seu "Diploma” de conclusão da formação secundária, cuja legitimidade é conferida pela média entre as notas obtidas no decorrer dos 3 últimos anos dessa formação escolar e no exame final, Abitur. Importante registrar que há possibilidades de transferência entre os diferentes segmentos escolares, ou mesmo, de ingressar em uma escola após ter concluído outra. Há também, mas em menor número, as Gesamtschule, ou seja, Escolas Integradas, nas quais a formação escolar não é segmentada após os 4 primeiros anos. Mas para ingresso na Universidade é imprescindível a realização do Abitur.

Apresentamos esse panorama para situar o fato de que a formação de professores na Alemanha e sua organização curricular correspondem também ao tipo de escola na qual os futuros docentes irão atuar. Retomaremos essa questão adiante, mas, antes de prosseguir, consideramos válido apontar algumas reflexões em torno dos debates sobre a relação entre teoria e prática em pauta nas últimas décadas.

Teoria e Prática: Pesos e medidas na FORMAÇÃO DO PROFESSOR DE HISTÓRIA

Sem desconsiderar os debates recentes em torno do currículo da formação docente em todas as áreas, com especial demanda pelo reconhecimento do 
estágio supervisionado como componente curricular, há que se problematizar a permanência de algumas dicotomias (teoria e prática, por exemplo) e heranças de percepções tecnicistas relativas ao espaço que as práticas e o estágio supervisionado ocupam na formação docente inicial (Silva, 2010).

Historicamente a noção de prática sempre foi associada ao estágio docente. Desde o final do século XIX os “exercícios práticos” já faziam parte do currículo da Escola Normal que, até a década de 1930, constituía-se no único espaço institucional de formação de professores no Brasil. Também foi na Escola Normal, ainda na década de 1930, que o estágio foi incluído no currículo. Este previa 20 horas de regência de aulas em classes dos grupos escolares, a serem realizadas pelos alunos no $4^{\circ}$ ano do curso.

No Brasil, a formação de professores de História especificamente só se iniciou com os primeiros cursos de História no próprio estabelecimento de universidades brasileiras a partir das décadas de 1930 e 1940 - o curso de História da Universidade do Distrito Federal (UDF), criado em 1935 (e extinto em 1939, reorganizado na recém-fundada Universidade do Brasil), e o curso da Universidade de São Paulo (USP), criado em 1934. Até então, os nomeados como historiadores eram intelectuais oriundos de diferentes formações: jornalistas, advogados, militares, médicos etc. Já se explorou bastante o lugar ocupado pelo Instituto Histórico e Geográfico Brasileiro (IHGB) na constituição dos estudos históricos no Brasil, mas a verdade é que até a década de 1930 os conhecimentos históricos eram produzidos sem a obrigação de profissionalizar uma nova geração para atuar no ensino propriamente.

O objetivo principal dessas instituições era formar professores para os atuais níveis de ensino fundamental e médio, mas já naquele momento a forma como esses cursos estavam estruturados era alvo de críticas, sobretudo no que concerne à relação entre a formação para o ensino e a formação para a pesquisa (Costa, 2009). Em 1939 instituiu-se no plano federal o primeiro "Curso de Didática” (Decreto-Lei 1190, de 4 abr. 1939) quando se organizou a Faculdade Nacional de Filosofia da Universidade do Brasil, que se se tornaria padrão para todas as outras Faculdades. Esse decreto instituiu o chamado esquema " $3+1$ ", pelo qual o estudante obtinha o diploma de bacharelado em área específica, em 3 anos, e acrescentava o diploma de licenciatura após frequentar o "Curso de Didática" por mais um ano (Nadai, 1985). 
Na década de 1940, por força de lei (Decreto-Lei 9092, de 26 mar. 1946), foram criados os Ginásios de Aplicação. Determinava-se a partir de então que os alunos do $4^{\circ}$ ano dos cursos de licenciatura recebessem nesses Ginásios (posteriormente Colégios de Aplicação) a formação didática, teórica e prática. A disciplina era nomeada como "Prática de Ensino" e, a partir de então, as pessoas que passaram por diferentes cursos de formação docente não separavam o sentido de estágio do sentido de prática. Um equivalia ao outro.

Em relação a essa questão vale notar que ainda nas décadas de 1950 e 1960 a maioria dos professores de História (de outras áreas também, é possível) que atuavam no interior eram leigos. Em entrevista concedida a Marieta de Moraes Ferreira, Vicente Tapajós, aluno da primeira turma do Curso de História da Universidade do Distrito Federal, professor catedrático do Colégio Pedro II e do Instituto de Educação e ainda da Universidade Federal do Rio de Janeiro (UFRJ), além de autor uma série de livros didáticos, lembra que:

A grande maioria dos professores do interior do Brasil, até mesmo em Estados como Rio de Janeiro e São Paulo, eram leigos. Quem dava aula de latim? O pároco. De História? Um jovem advogado ou um cidadão com mais leitura. De Matemática? Um militar. E de Física, de Química, de Ciências? Médicos, dentistas. (Ferreira, 2013, p.182)

Podemos pensar que historicamente a dimensão prática dos cursos de História (bem como de outras áreas) acontecia no próprio cotidiano de trabalho do docente. As disciplinas de cunho didático eram restritas à parte final do curso, desconectadas de discussões teóricas do campo de saber a ser ensinado, o que explica em parte a construção da cindida percepção relativa a teoria e a prática no curso. Elza Nadai lembra que na USP, por exemplo, a ênfase da formação assentava-se no conteúdo específico, o professor que soubesse o conteúdo saberia ensiná-lo. Valorizavam-se aí a ciência e a erudição, o diálogo com a educação não era determinante na formação do professor, as disciplinas específicas sim. No caso do professor de História a valorização da formação teórica específica estava identificada à memória da elite. O professor de História - produto dessa formação - era preparado para atuar nas escolas secundárias (em franca expansão desde a década de 1930) localizadas em sua maioria em centros urbanos com estudantes da classe média (Nadai, 1985, p.8-10). 
Nesse processo, tanto o espaço ocupado pela prática de ensino quanto o diálogo com a Educação eram desvalorizados, quase que reclusos na formação do docente. A partir da década de 1960 podem-se acompanhar mudanças substantivas na formação docente, como por exemplo, a fixação pelo Conselho Federal de Educação, pela primeira vez, da Prática de Ensino como componente do mínimo curricular pelo Parecer CFE n.292/1962. Os estágios supervisionados que efetivavam a prática deveriam cumprir esse mínimo, em escolas da comunidade, preferencialmente. Deixava assim de vigorar a obrigatoriedade do cumprimento do estágio em Colégios de Aplicação. Já o parecer CFE n.672/1969 estabeleceu a porcentagem mínima que as matérias pedagógicas deveriam ocupar na totalidade dos cursos de licenciatura, pelo menos 1/8 do total (Nadai, 1985, p.11-12).

Houve outras mudanças no que se refere à formação docente e, consequentemente, ao estágio nas décadas seguintes, mas para subsidiar a discussão proposta considera-se que as mais importantes foram as reformas realizadas após os debates e reinvindicações por mudanças no cenário educacional brasileiro nas últimas décadas do século XX, que em certa medida acompanharam o movimento internacional de profissionalização do ensino e da formação para o ensino. Na década de 1980, em meio à abertura política, dentre as questões pautadas nos debates relacionados à formação do professor de História, sobressaíam aquelas relacionadas a interrogações sobre o espaço que o conteúdo específico da área do conhecimento e o conteúdo didático e pedagógico deveriam ocupar no currículo. Os historiadores envolveram-se em tal debate, fazendo parte da comissão que entre 1981 a 1986 realizou a Avaliação dos Cursos de História no Brasil e depois elaborando propostas para as Diretrizes Curriculares Nacionais (CDN) para os cursos de graduação em História (Costa, 2009, p.5). A proposta inicial da Anpuh era que recaísse sobre os cursos de História a formação de um profissional único, sem distinção entre pesquisador e professor. Embora as DCNs para os cursos de História estabelecidas pelo parecer 492/2001 do CNE tenham tomado por base o texto escrito pela Anpuh, o documento não incorporou a proposta de estruturação em um único curso, reforçando a especificidade de diretrizes para a licenciatura e o bacharelado em História, o que motivou a reprovação das DCN pela Anpuh (Costa, 2009 , p.5). Aryana Lima observa que a mobilização dos historiadores em participar dessas discussões junto ao Ministério da Educação evidencia 
envolvimento na constituição de uma identidade para si por meio da sua ocupação e atuação na academia (ibidem, p.5).

Para o Ministério de Educação, portanto, os cursos de graduação, não apenas os de História, deveriam se adequar às determinações legais amparadas pelas propostas de DCNs e pelo Parecer CNE/CP 9/2001, de 8 de maio de 2001, que consolidaram a terminalidade e integralidade própria da Licenciatura em relação ao Bacharelado.

Na esteira das DCNs o Parecer CNE/CP 9/2001 traz uma concepção de prática e de estágio supervisionado como componentes curriculares específicos. Esse parecer objetiva transcender o modelo da racionalidade técnica e indica a necessidade de que os cursos de formação docente invistam no desenvolvimento de competências capazes de habilitar o futuro professor para a abordagem das questões e a resolução dos problemas que surgem no cotidiano escolar. Esse parecer visa complementar o que estabelece a Lei de Diretrizes e Bases da Educação Nacional - LDBN no 9.394/96. Esse parecer acompanha as "inovações" da LDBN no que diz respeito à formação docente e indica que a reforma na formação de professores deve considerar alguns princípios básicos como diretrizes para a organização curricular (ver p.51 desse documento). Como eixo articulador das dimensões teóricas e práticas o documento discute o lugar da prática como lugar distinto do estágio, enfatizando ambos como componentes curriculares. Mas é o Parecer CNE/CP 28/2001 que estabelece de modo claro a distinção entre a prática como componente curricular e o estágio.

A prática como componente curricular é, pois, uma prática que produz algo no âmbito do ensino. Sendo a prática um trabalho consciente cujas diretrizes se nutrem do Parecer 9/2001, ela terá que ser uma atividade tão flexível quanto outros pontos de apoio do processo formativo, a fim de dar conta dos múltiplos modos de ser da atividade acadêmico-científica. Assim, ela deve ser planejada quando da elaboração do projeto pedagógico e seu acontecer deve se dar desde o início da duração do processo formativo e se estender ao longo de todo o seu processo. Em articulação intrínseca com o estágio supervisionado e com as atividades de trabalho acadêmico, ela concorre conjuntamente para a formação da identidade do professor como educador. 
Sobre a carga horária o Parecer CNE/CP 2/2002 e a Resolução CNE/CP 2, de 19 de fevereiro de 2002, indicam que os cursos de formação docente obrigatoriamente precisam incluir 400 horas de Prática como Componente Curricular e 400 horas para Estágio Curricular Supervisionado. No entanto, o diálogo com professores que atuam no âmbito da formação de professores de História nas Faculdades de Educação e Ciências Humanas tem revelado que na "prática", a "teoria" - ou a relação entre a prática e a teoria - ainda é perpassada por conflitos de matizes distintas.

\section{A FORMAÇÃo DOCENTE do PROFESSOR DE História Na Alemanha: duas etapas, muitas Questões}

Conforme Ingrid Ceballos (1995, p.172), desde o início do século XIX antes, portanto, da unificação da República Federal Alemã (1871) - a Educação básica já era pauta de debates entre os ilustrados dos estados de origem germânica. Foi nesse contexto que Wilhelm von Humboldt, fundador da Universidade Investigativa de Berlin (atual Humboldt-Universität zu Berlin) e na condição de Secretário de Estado para Assuntos Culturais da Prússia, encaminhou a seus pares significativa reforma no sistema de ensino prussiano que serviria de pauta para futuros debates em matéria de Educação. Um dos aspectos abordados por essa reforma foi a sistematização da formação de professores no interior da referida Universidade, em uma perspectiva bastante pautada pelos ideais iluministas. De acordo com análise de Ceballos,

Mientras la escuela básica se apoyaba en un modelo pedagógico humanista basado en la confesionalidad - en Prusia de confesión protestante -, el modelo de la universidad investigativa que introdujo von Humboldt en Berlín (1810), se fundamentaba en la objetividad de la ciencia, Humboldt reorganizó el Gimnasio como escuela propedéutica de la universidad en el nuevo espíritu investigativo, y procuró la formación científica de su profesorado en la universidad. (Ceballos, 1995, p.173)

Vale ressaltar que esse foi um modelo experimentado na Prússia e, em paralelo à formação de professores na Universidade - voltada para futuros docentes do Gymnasium -, existiam também em outros estados as denominadas Escolas Normais, que formavam professores para o Magistério. No século 
XX, essa perspectiva formativa foi redefinida por demandas políticas, econômicas e sociais que emergiram no período pós-Primeira Guerra Mundial, demandando um novo perfil de cidadão e, portanto, novo perfil de professor. Nesse contexto são fundadas em 1920 as Escolas Superiores de Pedagogia, nas quais os alunos certificados pelos Gymnasium poderiam formar-se professores para lecionar nas "escola médias", ou seja, aquelas que proporcionavam um ensino considerado mais pragmático e adequado às demandas sociais. Em 1983 essas escolas são fechadas em sua grande maioria, e a formação de professores para todos os segmentos de ensino consolida-se como demanda a ser atendida pelas Universidades.

Apresentamos na introdução deste artigo um panorama geral e simplificado do sistema de ensino alemão atual, por natureza complexo e orgânico especialmente conectado com as demandas econômicas, políticas e sociais daquele país. Ante esse panorama, cabe-nos questionar: como organizar um currículo de formação docente que dê conta das finalidades distintas a cada percurso possível para formação secundária?

A análise dos documentos selecionados permite-nos afirmar que há um núcleo de disciplinas comuns a todos os licenciandos - independente da disciplina com a qual irá trabalhar e, também, da escola na qual irá atuar. E há variações de escala, especialmente no que diz respeito ao aprofundamento de conhecimentos das áreas específicas e no nível de exigência dos estágios realizados durante a primeira etapa da formação, concluída com o cumprimento dos devidos créditos e aprovação no "Primeiro Exame Estatal". ${ }^{8}$ A segunda fase, referente ao período de preparo para o serviço, denominado Refendariat, também é uma exigência comum a todos os futuros professores - desde os que atuarão na Grundschule até aqueles que se formam para exercer a docência no Gymnasium. Nesse sentido, entendemos que o currículo das licenciaturas na Bavária fundamenta-se na valorização da experiência prática como formativa e indispensável para habilitação como professor. Mas nesse percurso ainda há outras particularidades importantes, que devemos considerar.

Antes de prosseguir, cabe esclarecer que o currículo aqui apresentado refere-se ao curso de licenciatura ofertado pela Universidade Julius Maximilian, fundada em 1402, localizada na cidade de Würzburg, cuja formação histórica data do ano 704 . 
De posse de seu Diploma de Conclusão da Formação Secundária o futuro estudante se encaminha à universidade para escolher, de acordo com o que sua nota lhe permite, a graduação que pretende cursar. Quem deseja ser professor escolhe ser professor e então precisa fazer mais outras duas escolhas: o que lecionar e em qual escola lecionar. Na Bavária é preciso escolher pelo menos duas habilitações em áreas de conhecimento específicas, em combinações que acabam por ser influenciadas pelo calendário das provas estatais. Nesse sentido, o estudo da História como disciplina escolar vincula-se necessariamente ao estudo do Alemão, Inglês, Francês ou Latim como primeira área específica do conhecimento. Vale ressaltar que nem todas as combinações estão disponíveis para a formação visando diferentes escolas - a combinação Latim e História ou Francês e História, por exemplo, só é possível para os futuros professores do Gymnasium.

Na Uni-Würzburg o currículo de todas as licenciaturas é composto por disciplinas da área das Ciências da Educação e disciplinas das duas áreas específicas do conhecimento, escolhidas para habilitação dupla. As primeiras são frequentadas com outros professores em formação, e as demais, junto aos estudantes que optaram pelo estudo nos níveis de Bacharelado e de Magister, que no Brasil seria equivalente a uma especialização na área do conhecimento. Até o Processo de Bolonha, ${ }^{9}$ os estudantes do Lehramt, ou Licenciatura, não precisavam frequentar as aulas das disciplinas consideradas específicas do campo da Educação. Bastava que eles estudassem os pontos do programa das referidas disciplinas e fossem aprovados nos exames finais. No entanto, após a reforma das políticas do Ensino Superior no esforço de aproximação entre os diversos países da União Europeia, tornou-se obrigatório frequentar seminários e aulas também na Faculdade de Educação. Ainda assim, os estudantes desfrutam de considerável autonomia no decorrer da formação superior, podendo organizar sua grade curricular, assim como a realização dos estágios com relativa liberdade.

Como já dissemos, as disciplinas da área das Ciências da Educação são comuns a todos os estudantes dos cursos de licenciatura, independentemente da escola na qual irão atuar. São estas: Pedagogia geral, Pedagogia escolar e Psicologia. As disciplinas das áreas de conhecimento também são em sua grande parte semelhantes, variando o número de créditos que devem ser cumpridos em disciplinas de aprofundamento sobre o conhecimento científico referente 
às habilitações escolhidas. Para tratar especificamente da organização curricular e dos estágios realizados iremos focar a grade de ensino dos estudantes que optam por lecionar História como disciplina escolar na Realschule. Sempre que pertinente apontaremos semelhanças e diferenças com as outras formações. Conforme o currículo disponibilizado no site da Julius Maximilian Universität,

(1) O curso de Licenciatura para Realschule tem um tempo de estudo regular de 7 semestres, no qual todos os 210 créditos ${ }^{10}$ precisam ser cumpridos. (organizados na seguinte grade curricular)

a) O curso de duas "disciplinas escolares" que correspondem [cada uma] a 72 créditos, dos quais 60 créditos são em disciplinas relacionadas ao conhecimento científico da área e 12 créditos para conhecimentos da didática;

b) O curso das Ciências da Educação na extensão de 35 créditos da Pedagogia Geral, Pedagogia Escolar e Psicologia ...;

c) A monografia ... que corresponde 10 créditos.

d) Uma "prática livre" que corresponde a 15 créditos. ${ }^{11}$

Com base nessa organização curricular temos uma proporção de 35 créditos em disciplinas vinculadas às Ciências da Educação para 144 em disciplinas da área do conhecimento específica, e 20\% destas últimas se referem à parte Didática. Enquanto as disciplinas da área de Educação são de responsabilidade da Faculdade de Ciências da Educação, as disciplinas referentes às habilitações específicas são de responsabilidade das faculdades/institutos correspondentes. No caso da formação docente em História, as disciplinas são ofertadas pelo Instituto de Filosofia, e estruturadas conforme a Tabela 1.

As disciplinas são organizadas de forma modular. No caso da área didática a disciplina é denominada Didática da História e Metodologia da aula de história (ou ensino de História), módulo inicial e de aprofundamento. No caso da área do conhecimento específica, temos as seguintes disciplinas: Introdução à História Antiga ( 8 créditos); Introdução à História Medieval (8 créditos); Introdução à Idade Moderna ( 8 créditos); Introdução à História Contemporânea ( 8 créditos); Introdução à História Regional (8 créditos) estas podem ser realizadas no período de 1 a 2 semestres. E além dessas, temos: Módulo de especialização em História ( 9 créditos); Módulo de aprofundamento em História (11 créditos); Módulo de aprofundamento (8 créditos) e 


\begin{tabular}{|c|c|c|}
\hline Bereich bzw. Teilbereich & \multicolumn{2}{|c|}{ ECTS-Punkte } \\
\hline Fachdidaktik Área Didática & \multicolumn{2}{|c|}{12} \\
\hline Pflichtbereich Domínio obrigatório & 12 & \\
\hline Aufbaumodul Didaktik der Geschichte Módulo Inicial Didática & a História & 6 \\
\hline \multicolumn{3}{|c|}{ Vertiefungsmodul Didaktik Geschichte $\begin{array}{c}\text { Módulo de Aprofundamento Didática da } \\
\text { História }\end{array}{ }^{2}$} \\
\hline gesamt & & 12 \\
\hline
\end{tabular}

\begin{tabular}{|l|c|c|}
\hline \multicolumn{1}{|c|}{ Bereich bzw. Teilbereich } & \multicolumn{2}{c|}{ ECTS-Punkte } \\
\hline Fachwissenschaft Área do conhecimento & \multicolumn{2}{|c|}{60} \\
\hline Auflichtbereich Domínio obrigatório & 60 & \\
\hline Spezialisierungsmodul Geschichte Módulo de Especialização História & 9 \\
\hline Vertiefungsmodul Geschichte Módulo de aprofundamento História & 11 \\
\hline gesamt & & 60 \\
\hline
\end{tabular}

Tabela 1: Grade Curricular do curso de Licenciatura, habilitação em História ${ }^{12}$

Módulo de aprofundamento em História “Novíssima” (ou do Tempo Presente, ou Nova e Contemporânea).

No caso da formação de professores para Gymnasium há um número maior de créditos a serem cumpridos nos módulos de aprofundamento do conhecimento específico, enquanto a formação de professores para atuação na escola média exige um número menor. Os módulos introdutórios são cursados de forma conjunta por todos os estudantes de licenciatura que optam pela História como área de conhecimento.

Com relação aos estágios realizados no decorrer da primeira parte da formação, eles são organizados em 4 etapas distintas: um estágio em empresa/fábrica; um estágio de orientação, um estágio escolar didático-pedagógico e, por fim, um estágio na área didática específica. O primeiro é de responsabilidade do aluno e consiste na observação, por cerca de 8 semanas, em um ambiente de trabalho que não seja a escola, com vistas a possibilitar ao estudante "um olhar aprofundado no mundo das profissões" ${ }^{13}$ o segundo e o terceiro são acompanhados por docentes da Faculdade de Ciências da Educação, e o último é acompanhado por docentes da área específica do conhecimento - no caso, é preciso realizar esse estágio apenas em uma das habilitações escolhidas. 
O estágio com maior carga horária (150 a 160 horas-aula) é o "Estágio escolar didático-pedagógico", que só pode ser feito após o "Estágio de Orientação", e deve possibilitar ao professorando o conhecimento de seu futuro campo de atuação, sob o acompanhamento e a supervisão de um professor da escola. Conforme orientações do curso:

Os estudantes devem conhecer o campo de trabalho do professor especialmente sob pontos de vista didático-pedagógicos, e junto a isso princípios didáticos específicos das disciplinas também devem ser trazidos à tona.

Por volta do final do estágio escolar didático-pedagógico, o professor responsável conduz com o estudante uma minuciosa orientação, na qual eles sintetizam as observações realizadas durante o estágio. Essa conversa ajudará os estudantes a avaliarem de forma realista sua aptidão e inclinação para a exigente profissão ...

O Estágio escolar didático-pedagógico visa, dentre outros, os seguintes objetivos:

- Envolvimento na aula;

- Observação da aprendizagem e da socialização dos alunos;

- Conhecimento de diferentes metodologias de aula;

- Preparo, condução e análise de variadas tentativas de aula própria;

- Organização conjunta de atividades;

- Conhecimento das atividades extraclasse de um professor;

- Responsabilização por atividades simples de organização. ${ }^{14}$

Essas são partes das orientações para estágio escolar de futuros professores da Realschule, que correspondem também às da Mittelschule. No caso do Gymnasium, os estudantes podem optar pela realização desse estágio - que assume contornos um pouco mais específicos como, por exemplo, o preenchimento de um caderno de campo - ou pela participação em oficinas de formação.

Nosso interesse aqui é destacar como a aproximação com a prática pedagógica é organizada pelo currículo nessa primeira etapa de formação docente, possibilitando a inserção do estudante em momentos distintos e com finalidades distintas no contexto escolar. Entendemos que essa estratégia prioriza, nesta etapa, a apreensão da particularidade da escola como um campo de trabalho. Ao que nos parece, a "parte prática" dessa etapa visa principalmente a 
percepção da docência como profissão com nível de exigência elevado, enquanto a parte "teórica" cuida não apenas dos conhecimentos específicos, mas também das estratégias didáticas próprias a esses conhecimentos. Há, assim, preocupação em possibilitar ao aluno oportunidades de inserção no contexto escolar que lhe permitam pôr à prova suas aptidões e inclinações mediante os desafios que envolvem esta profissão. Nessa perspectiva, nos parece que a formação docente na Alemanha vincula-se a uma identidade profissional estabelecida e legitimada pelo lugar que a profissão assume na organicidade social, ficando matizadas as especificidades relativas às identidades vinculadas às disciplinas de formação.

Apenas o último estágio curricular prevê uma aproximação maior com a área de atuação específica, mas mesmo assim em apenas uma das habilitações, conforme escolha do aluno. O estágio na área didática específica

É realizado uma vez por semana durante um semestre e compreende pelo menos 4 horas-aula, incluindo orientação. Relaciona-se a uma das duas áreas de conhecimento específico escolhidas.

Os estudantes devem vivenciar as primeiras experiências relacionadas aos planejamentos específicos da área e à análise de planos de aula, assim como experiências de aula. Dentro do possível não deve ser realizado antes do $3^{\circ}$ semestre nem depois do $5^{\circ}$ semestre. $\mathrm{O}$ estágio estará relacionado a um seminário ofertado no mesmo semestre.

Nesse estágio os estudantes visam os seguintes objetivos:

- Conhecimento das especificidades da forma de trabalho com a área específica com base em modelos de aula individuais, exemplos de aula e projetos de aula em anos escolares diferentes;

- Preparo e análise de planos de aula;

- Pelo menos uma "tentativa" de aula. ${ }^{15}$

Uma vez cumprido o currículo dessa primeira etapa, que envolve a formação nas disciplinas das Ciências da Educação, nas disciplinas das duas habilitações escolhidas, os estágios, a monografia e ainda uma parte da formação livre - que corresponderia à parte das disciplinas eletivas no currículo brasileiro -, o estudante está apto a realizar o "Primeiro exame estatal", que lhe dará o certificado de conclusão do curso necessário para realização da próxima 
etapa de formação, o Refendariat ou estágio probatório, com duração de 2 anos para todas as formações docentes.

O Refendariat é a etapa da formação docente alemã que possivelmente mais se diferencie do currículo brasileiro para as licenciaturas. Mas, para além do currículo em sua dimensão formativa, essa etapa se vincula também a uma estratégia de inserção docente no contexto escolar que certamente atende a demandas socioeconômicas e políticas e requer toda uma organicidade que permita o funcionamento desse sistema.

O $1^{\circ}$ ano do Refendariat é realizado nas chamadas Seminarschule, ou seja, Escolas Seminário nas quais os professorandos acompanham especialmente os professores de suas habilitações específicas - mas não somente - e assumem uma carga horária de até 11 horas-aula. Nesse período eles são sempre acompanhados por um professor supervisor. Além disso, participam de seminários junto a outros colegas que se encontram na mesma etapa formativa uma vez por semana. No $2^{\circ}$ ano do estágio probatório os professorandos são designados para atuar nas escolas regulares do sistema de ensino, conforme as vagas disponíveis, com uma carga horária de até 17 horas-aula semanais, devidamente remunerada. ${ }^{16}$

Nesse $2^{\circ}$ ano do Refendariat os professorandos são responsáveis pelas disciplinas que lecionam e por todas as tarefas advindas da atividade docente - ou seja, já atuam como professores. No entanto, ainda são supervisionados por um professor na instituição de atuação e devem comparecer periodicamente aos seminários de estudos na mesma Escola Seminário onde realizaram a primeira etapa do estágio probatório, mas em uma frequência menor - no total são realizados cerca de 12 seminários durante essa etapa.

Após concluir este $2^{\circ}$ ano de atuação efetiva na escola, o professorando - e talvez aqui o termo se encaixe particularmente bem - deve prestar o "Segundo Exame Estatal". Para além de serem avaliados em sua prática docente pela banca de professores, eles ainda prestam prova oral e escrita sobre os conhecimentos específicos em Educação, nas áreas de atuação específicas, e precisam elaborar mais uma monografia relacionada a Pedagogia, Psicologia ou Didática de uma das disciplinas de atuação. Ao fim, todas as avaliações são consideradas para o cálculo da nota final, atribuída entre 1 e 5 pontos, em uma escala na qual a nota 1 é a máxima e a 5 a mínima. 
De posse do diploma e dessa nota global final o professor é considerado apto para atuar formalmente como docente e fica, portanto, disponível para prestar seus serviços ao Estado, que convoca e aloca os professores conforme seu desempenho no "Segundo Exame Estatal". ${ }^{17}$ Atualmente, dado o número considerável de profissionais docentes e o reduzido número de vagas disponíveis, a nota de corte é de 1,3 ponto - ou seja, quase a nota máxima. Uma vez convocado para trabalhar no sistema de ensino público o professor é efetivado, com uma remuneração que, no início dos anos 2000, girava em torno de 4 mil euros para atuação no sistema de ensino público regular (Fichtner; Benites, 2005).

Esse olhar sobre a formação docente na Alemanha suscita algumas reflexões, especialmente em relação à vinculação da identidade profissional a uma disciplina específica que, conforme esse currículo, pareceu-nos subsumida. As análises e leituras realizadas indicam-nos que a organicidade do sistema de ensino alemão concorre para que a profissão docente assuma, naquela sociedade, um lugar social valorizado em sua dimensão simbólica e prática. Porém, chamou-nos atenção o lugar que a Didática ocupa nessa organização curricular como módulo da área específica do conhecimento, indicando-nos o reconhecimento de que cada disciplina possuiu metodologias próprias para seu ensino no contexto escolar. Talvez essa seja uma das justificativas para as aproximações recentes que observamos de pesquisadores brasileiros com teóricos da Didática da História alemães, como por exemplo, Jörn Rüsen. ${ }^{18}$

Mas, se há tentativas de aproximações teóricas, diálogos relacionados à prática ainda carecem de intensificação. Imaginamos o quão potente seria um olhar mais detido sobre esta segunda etapa da formação docente na Alemanha, denominada Refendariat. Mas os diálogos precisam ser estabelecidos não apenas num nível internacional. Eles também se fazem necessários entre as diferentes instituições de formação docente em nosso país, que têm adotado estratégias distintas no decorrer deste percurso. Por isso achamos válido apresentar a seguir como professores do curso de História na Udesc vêm lidando com os desafios postos pelas demandas do tempo presente nas disciplinas de estágio supervisionado. 
ESTÁGIO SUPERVISIONADO E A FORMAÇÃO DOCENTE: ENSINO DE História COMO CAMPO DE ESTUdOS E PESQUISAS NA Universidade do Estado de Santa Catarina (Udesc)

O curso de licenciatura em História da Udesc teve sua primeira turma no $1^{\circ}$ semestre de 1990, após a extinção do curso de Estudos Sociais que funcionava desde 1974. A partir do $2^{\circ}$ semestre de 1995, passou a oferecer dupla habilitação, as modalidades de bacharelado e licenciatura. Em 2003, diante das demandas anunciadas pelas Resoluções CNE/CP números 1/2002 e 2/2002, o percurso curricular teve sua carga horária de estágio supervisionado aumentado (414 h-a) e foram acrescidas disciplinas específicas relativas às práticas curriculares, ofertadas ao estudante a partir do $3^{\circ}$ semestre do curso: Prática Curricular: Imagem e Som I e II e Prática Curricular: Patrimônio Cultural I e II (432 h-a).

A partir de outubro de 2011 o formato de Curso passou por significativa mudança: o bacharelado foi extinto na habilitação. Tal extinção visou o cumprimento da legislação e as determinações do Conselho Estadual de Educação (CEE), que passaram a exigir a terminalidade e integralidade próprias da licenciatura em relação ao bacharelado. Novas discussões foram iniciadas com vistas a construir duas matrizes diferentes que atendessem as especificidades de cada percurso formativo.

A nova matriz para o curso de licenciatura em História da Udesc foi aprovada em 2013, ${ }^{19}$ tendo a primeira turma iniciado no $1^{\circ}$ semestre de 2014 (a nova turma do bacharelado iniciou no $1^{\circ}$ semestre de 2015). O novo currículo possui 3.402 horas-aula, assim distribuídas: 486 h-a de estágio curricular supervisionado a partir do início da segunda metade do Curso; 486 h-a de prática curricular a partir da primeira fase do Curso; 2.160 h-a de conteúdos curriculares de natureza científico-cultural e 270 h-a de atividades complementares.

A necessidade de atender disposições legais não oculta as rugosidades, disputas e conflitos de interesses nas discussões que visam construir uma nova matriz curricular. Aumentar ou reduzir cargas horárias de disciplinas existentes, deslocar disciplinas no itinerário do curso e excluir disciplinas são sempre pontos muito sensíveis que dizem respeito não apenas ao currículo em si, mas a interesses relacionados à carreira do professor do curso, sua área de concurso ou pesquisa etc. Currículos são efeitos de poder, justamente porque as 
discussões e debates que o envolvem são travados no âmbito do exercício de poderes, e sobre essa questão Foucault (1998) é taxativo: não há relação de poder sem a constituição de um campo de saber, nem saber que não constitua relação de poder.

Ao analisar os diferentes currículos do curso de história da Udesc desde 1990 constatamos ampliação de disciplinas curriculares de cunho prático. Houve, por exemplo, significativa ampliação da carga horária das disciplinas de Estágio Supervisionado. Um estudante do curso que ingressou em $1990 \mathrm{fez}$ o seu Estágio Supervisionado (à época nomeado Prática do Ensino de História) apenas no último ano do curso, e em um semestre. Quem ingressou em 1998 cursou as disciplinas de Metodologia e Prática do Ensino de História I, II e III a partir do $5^{\circ}$ semestre. Em 2004 o estudante passou a ter disciplinas de práticas curriculares de Imagem e Som I e II e Patrimônio Cultural a partir do $3^{\circ}$ semestre, e Estágio Curricular Supervisionado I, II e III a partir do $5^{\circ}$ semestre. Em 2014 o estudante tem uma disciplina a mais de prática curricular: "Ensino de História e suas Linguagens" I e II, ofertada a partir do $1^{\circ}$ semestre do curso, com aumento da carga horária das práticas curriculares e do estágio curricular supervisionado.

As disciplinas de Estágio Curricular Supervisionado foram reorganizadas quanto à sua carga horária, mas sofreram poucas alterações quanto à dinâmica que vem sendo desenvolvida desde 2005: Estágio Curricular Supervisionado I (90 horas-aula), Estágio Curricular Supervisionado II (180 horas-aula) e Estágio Curricular Supervisionado III (216 horas-aula). Nessa disciplina - realizada no âmbito das Escolas Públicas de Educação Básica de Florianópolis - o estágio docente é entendido como componente curricular do curso de História que incorpora a pesquisa, constituindo-se em momento teórico/prático no qual a docência e as demandas postas ao ensino de História, no presente, são problematizadas e investigadas. Nessa direção as atividades do estágio estão integradas às atividades do Laboratório de Ensino de História (LEH) e do grupo de pesquisa Ensino de História, memória e culturas (CNPq/Udesc), que por sua vez é espaço das atividades relacionadas aos estudantes de graduação bolsistas de Iniciação à Pesquisa (IC) e bolsistas do Programa Institucional de Bolsa de Iniciação à Docência (Pibid), bem como os de pós-graduação, mestrado e doutorado da História e da Educação. 
A disciplina de Estágio Curricular Supervisionado $\mathrm{I}^{20}$ é ofertada no $6^{\circ}$ semestre do Curso. Nessa primeira etapa o estudante passa a ter contato com leituras mais específicas relativas aos saberes escolares e saberes docentes. Eles têm uma parte da carga horária em sala de aula toda a semana, e uma parte é destinada ao trabalhado nas escolas. Em grupos, de no máximo três estudantes, eles são colocados numa das turmas de uma escola pública campo de estágio ${ }^{21}$ e passam a observar aulas de História. Nesse primeiro momento eles precisam fazer relatórios de observação com a proposta de identificar usos do livro didático, do quadro, de outros materiais pedagógicos, formas de o professor organizar e ministrar o conteúdo, interação entre os estudantes e entre estes e o professor, cultura escolar etc. Os estudantes - se chamados pelo professor da turma (denominado supervisor) ${ }^{22}$ - podem também ajudar nas atividades em sala de aula. Depois desse tempo de observação que dura em média 4 semanas, cada grupo elabora uma oficina (baseada em tema prévio dado pelo professor da escola) e seu material didático, e a desenvolve na sala de aula. O desenvolvimento é todo orientado pelo professor da disciplina de Estágio, que também acompanha os estagiários quando eles estiverem fazendo a oficina na escola. O trabalho final da disciplina é a oficina e um artigo escrito individualmente sobre uma das questões propostas para observação, dialogando com os textos de cunho teórico estudados em sala.

As disciplinas de Estágio Curricular Supervisionado II e III possuem uma lógica de trabalho que as interliga, pois o trabalho é realizado ao longo de um ano letivo, numa mesma escola e turma. A disciplina de Estágio Curricular Supervisionado II, ofertada no $7^{\circ}$ semestre, possui também uma parte desenvolvida em sala de aula, estudos de dissertações e teses que têm por objeto o ensino de História, e uma parte nas escolas. Também em grupos, de no máximo três estudantes, eles são colocados numa das turmas de uma escola pública campo de estágio e passam a observar aulas de História. Inicialmente a dinâmica é muito parecida com a disciplina de Estágio I e também requer relatórios individuais, mas é mais específica porque objetiva uma maior interação com a turma e deve resultar no preparo de um projeto de ensino e de pesquisa que será desenvolvido com a mesma turma na disciplina de Estágio Curricular Supervisionado III. Essa etapa dura um tempo maior do que a anterior, 8 semanas. Os professores supervisores - no caso, o professor da escola - são instigados a apresentar demandas aos alunos, solicitando textos didáticos ou outros 
materiais sobre um tema específico, convidando para auxiliar nas atividades em sala de aula ou mesmo na escola. Nesse semestre também os alunos elaboram e ministram uma oficina. O trabalho final dessa disciplina, além da oficina, é o projeto de ensino e de pesquisa que será desenvolvido no semestre seguinte. $\mathrm{O}$ Estágio Curricular Supervisionado III ofertado no $8^{\circ}$ semestre do curso dá continuidade ao semestre anterior, e os estudantes retornam do recesso de julho já no calendário da escola - ou seja, quando a escola recomeça as aulas, eles recomeçam também. Paralelamente às aulas há um encontro na Universidade durante a semana, momento de orientações relativas aos planos de aula, materiais que serão usados etc., socialização das experiências e também discussão de algum tema específico que surja no decorrer do semestre, relativo à escola e às aulas de História. Eles se organizam, dão as aulas sob orientação e acompanhamento do professor de estágio e do professor da escola. Os estudantes ficam responsáveis pela turma durante um período que dura entre 8 e 12 semanas, podendo durar mais se houver feriados ou paralisações nos dias das aulas. Após o término das aulas os alunos precisam fazer individualmente um artigo que analise um dos resultados da pesquisa proposta no projeto de ensino e de pesquisa. ${ }^{23}$ Em grupo fazem o relatório final do Estágio, que abrange as experiências dos dois semestres letivos e deve conter para além da parte descritiva, também a analítica. O trabalho final da disciplina, além das aulas ministradas, são justamente o artigo individual e o relatório. $\mathrm{O}$ trabalho é exaustivo para estagiários e professores, mas o objetivo é deslocar o eixo da formação docente reduzida à parte prática do curso "subordinada à teoria" e investir na construção de que o estágio docente também é atividade teórica de conhecimento, fundamentação, diálogo e intervenção, entre outras dimensões políticas.

Contudo, a forma como o estágio foi estruturado só funciona adequadamente para estudantes que não atuem no mercado de trabalho efetivamente. Os estudantes que trabalham fazem seu estágio em escolas à noite, mas têm muito mais dificuldade em acompanhar todas as atividades com a qualidade que o projeto requer. Não apenas pela sua falta de tempo ao longo do dia para participar de reuniões de orientação ou planejamento e outras atividades na escola (Conselhos de Classe, Semanas culturais etc.), mas também porque à noite o Ensino Fundamental só é ofertado nas turmas de Educação de Jovens e Adultos, ${ }^{24}$ e o Ensino Médio, que também é ofertado de forma regular, tem carga horária reduzida (duas aulas semanais de 40 minutos). ${ }^{25}$ Além disso, o/a 
professor/a de História na escola, irrenunciável parceiro/a nesse processo de formação, também tem menos tempo para o diálogo com os alunos, porque à noite encerra-se uma trajetória de trabalho em que ele/ela muitas vezes ministra 12 ou até 15 aulas. Essa é uma questão que, muito embora esteja presente e seja alvo de preocupações, não se conseguiu vencer. Outra questão pertinente é que apesar de 3 décadas de debates, a função do docente da Educação Básica e o espaço da escola ainda são vistos por parte significativa dos estagiários (e de muitos de nossos colegas na Universidade) como o espaço da transmissão de conhecimentos produzidos nos espaços acadêmicos. O espaço da sala de aula e a atividade docente na Educação Básica ainda seguem sendo percebidos como o espaço de reprodução do conhecimento baseado em uma racionalidade técnico/instrumental. Parte-se de uma concepção de que a escola é o espaço de divulgação social dos conhecimentos científicos e que o professor é o responsável por adequar e facilitar a apropriação destes pelos alunos. Os saberes que deveriam ser ensinados, organizados nos programas e currículos, são vistos como "oriundos de uma base científico-cultural ampla, através de meios e procedimentos acertados, escolhidos num 'receituário ou arsenal' construído e fundamentado cientificamente nos conhecimentos oferecidos pela psicologia, psicopedagogia e didática" (Monteiro, 2007, p.81). Além disso, para realizar um adequado trabalho de orientação e acompanhamento de estágios nas escolas, mesmo professores que possuem carga horária específica de orientação por aluno, caso da Udesc, acabam trabalhando muito mais que as 40 horas regulamentares quando também passam a fazer parte de programas de pósgraduação. Não que atualmente a maioria dos colegas que atuam em ensino, pesquisa e extensão também não o façam. Contudo, quando o Estágio Supervisionado é pensado e percebido como uma disciplina curricular de cunho teórico-prático, seu funcionamento é um tanto mais específico e complexo que as demais disciplinas do currículo. Apenas para ressaltar uma de suas dimensões, qualquer disciplina de Estágio Curricular Supervisionado, vista desta perspectiva, possui trabalho articulado em sala de aula e em campo, não pode prescindir das discussões teóricas e muito menos das idas ao campo, das reuniões com os docentes da escola, das orientações e acompanhamentos das aulas dadas pelos estagiários, até do acompanhamento da documentação legal relativa a seguros de vida etc. Quando se decide também fazer parte de programas de pós-graduação, ele está deliberadamente escolhendo trabalhar 
muito mais - ou isso, ou a negligência de seu trabalho na disciplina de Estágio, o que seria uma irresponsabilidade.

\section{AfINAL, QUAL MEDIDA?}

O intuito deste artigo não foi apresentar resultados ou mesmo respostas para um debate que, a nosso ver, ainda terá muitos embates pela frente. Mas, como o próprio título anuncia, nosso esforço foi levantar algumas questões sobre estratégias distintas de formação docente e refletir sobre elas, especialmente na relação estabelecida entre teoria e prática - ou entre os pesos e medidas conferidos ao conhecimento específico e à formação pedagógica para atuação no contexto escolar.

Ao pensarmos especificamente a formação docente em História, esbarramos nas questões que envolvem as relações entre licenciatura e bacharelado, que nos últimos anos também discutiram se o curso de História deve ou não ofertar concomitantemente a dupla habilitação, bem como a relação entre ensino ensino/pesquisa, entre História e Educação, das disciplinas teóricas com o estágio, a relação entre Ensino Fundamental e o Ensino Médio, entre a graduação e a pós-graduação etc. - questões que remontam debates e combates relativos à própria identidade do profissional de História e sua área de atuação, travados na década de 1980. Tais discussões que ressoam no presente assentaram-se em duas propostas: uma que defende uma única formação para atuação na pesquisa e no ensino: a formação do profissional de História (posição da Anpuh), e outra que defende percursos formativos diferentes justamente porque se compreende que a formação docente requer componentes pedagógicos específicos (posição defendida por profissionais ligados à Anped e às Faculdades de Educação) (Costa, 2009). A questão que nos parece relevante aqui não é se um curso de graduação pode ser capaz de preparar um profissional para atuar como professor de História na Educação Básica e na pesquisa igualmente, mas sim, quais são os limites e possibilidades dessa formação, considerando-se o tempo e os currículos dos cursos de formação. E ainda, como essa formação incide sobre a legitimação de uma identidade profissional docente, atualmente em luta para deslocar-se - ou descolar-se - da representação do magistério como sacerdócio, por meio da afirmação cotidiana da profissão docente. 
Ao que nos parece, no contexto de formação alemã, a questão apresenta-se diluída a partir do momento em que não se escolhe o "curso", mas a profissão. Nesse sentido, a formação do professor, mesmo com considerável carga horária nas disciplinas referentes às habilitações, apresenta-se fortemente vinculada à prática pedagógica no contexto escolar, atenta a demandas de diferentes matizes. A própria estratégia da habilitação dupla também concorre para que a identidade docente se vincule mais à natureza da escola na qual se atua do que estritamente à disciplina que se leciona - o que não significa que essa relação e suas tensões inexistam. Avaliar as ressonâncias dessa estratégia formativa na elaboração do conhecimento histórico escolar é tarefa merecedora de maior atenção.

Enquanto isso, no Brasil, nós, formadores de professores de História, somos chamados a trilhar um percurso incerto rumo a destinos possíveis. Se, por um lado, caminhamos a passos truncados em direção ao reconhecimento das disciplinas de prática e estágio supervisionado como componentes curriculares em tempos de insegurança e desvalorização da profissão docente, por outro, as discussões em torno da regulamentação da profissão de Historiador não apontam para uma caminhada menos incerta.

No Brasil, a dimensão prática da formação é bastante reduzida na etapa inicial de formação. Tal dimensão vai se efetivar em serviço, com o jovem professor iniciando sua prática atuando como substituto ou admitido em caráter temporário nas redes públicas. Na Alemanha, observa-se que a formação docente inicial enfatiza a dimensão prática no processo de formação, sem desconsiderar a relação entre teoria e prática. As escolas formadoras são as responsáveis por essa prática. Contudo, mesmo a despeito desse formato também a formação do professor de História na Alemanha sofre críticas que se aproximam daquelas feitas em relação ao caso brasileiro, especialmente no que concerne a cisões entre conhecimento histórico profissional, acadêmico, e o saber histórico escolar. Em suas análises sobre a didática da História, Jörn Rüsen (2006) chama atenção para mudanças e reorientações relativas à didática da História no contexto alemão, observadas entre as décadas de 1960 e 1970. A concepção hermenêutica da didática da história teria sido alterada, deslocando o entendimento padrão (e dominante) de que ela seria uma abordagem formalizada a fim de transformar historiadores em professores de História para atuar nas escolas primárias e secundárias. Enfim, a didática seria 
a disciplina responsável pela mediação entre a história como disciplina acadêmica e o aprendizado histórico e o saber escolar. Vista desta perspectiva, ela não teria relação com o trabalho dos historiadores propriamente. A reorientação da didática da História para uma concepção de que ela seria uma disciplina específica com suas próprias questões, concepções teóricas e operações metodológicas, que dimensionaria as formas e funções da História na vida prática, teria sido um reflexo tanto de mudanças culturais mais gerais quanto no sistema educacional, bem como de uma crise de legitimidade do ensino de História no contexto alemão. Mesmo a despeito dessa mudança paradigmática, Rüsen enfatiza certa permanência de concepções de historiadores que tendem a exilar a didática do campo da História. A formação dos professores ainda estaria assentada na lógica do "transporte do saber histórico cientifico para os setores não científicos”. Para Rüsen "a externalização e a funcionalização da didática são o reflexo de uma concepção estreita da ciência, por parte dos historiadores profissionais" (Rüsen, 2007, p.89).

Enfim, em nenhum momento foi de nosso interesse emitir juízo de valor ou mesmo comparar realidades que são, dado o contexto sócio-histórico e cultural, bastante distintas. Mas esperamos que as reflexões aqui apresentadas possam contribuir para as problematizações que se adensam em tempos de questionamentos acerca da formação e do fazer docente. E, principalmente, para repensarmos significados, potencialidades e limitações que tencionam diferentes currículos para formação docente em História - ainda sem encontrar a medida do equilíbrio entre teoria e prática, neste tempo e espaço em que formamos e nos formamos professores.

\section{REFERÊNCIAS}

CEBALLOS, Ingrid Müller de. La Formación docente en Alemania: una ojeada histórica. Revista Educación y Pedagogía, Facultad de Educación, Universidad de Antioquia, Colombia, n.14 y 15, p.170-177, 1995. Disponível em: http://aprendeenlinea.udea.edu.co/revistas/index.php/revistaeyp/article/view/5586/5008; Acesso em: 20 mar. 2015.

CERRI, Luis Fernando. Ensino de história e consciência histórica. Rio de Janeiro: Ed. FGV, 2011.

COSTA, Aryana Lima. As prescrições para a formação de historiadores no Brasil. In: SIMPÓSIO NACIONAL DE HISTÓRIA, 25. 2009, Anpuh, Fortaleza. Anais ele- 
trônicos... Disponível em: http://anpuh.org/anais/wp-content/uploads/ANPUH. S25.pdf; Acesso em: 25 mar. 2015.

FERREIRA, Marieta de Moraes. A História como ofício: a constituição de um campo disciplinar. Rio de Janeiro: Ed. FGV, 2013.

FICHTNER, Bernd; BENITES, Maria. O ofício do professor na Alemanha - uma entrevista (por Marcos Villela Pereira). Educação, Porto Alegre, RS, ano XXVIII, n.3 (57), p.535-546, set./dez. 2005.

FOUCAULT, Michel. Microfísica do poder. Trad. e org. Roberto Machado. 13.ed. Rio de Janeiro: Graal, 1998.

FREIRE, Paulo. Pedagogia da autonomia: saberes necessários à pratica educativa. 49.ed. São Paulo: Paz e Terra, 2014.

GOERGEN, Pedro. O sistema de ensino e a formação de professores na Alemanha. In: .; SAVIANI, Dermeval (Org.) Formação de professores: a experiência internacional sob o olhar brasileiro. Campinas, SP: Ed. Autores Associados, 1998. p.13-72.

LIMA, Licínio C.; AZEVEDO, Mario Luiz Neves de; CATANI, Afrânio Mendes. O Processo de Bolonha, a avaliação da educação superior e algumas considerações sobre a Universidade Nova. Avaliação, Campinas e Sorocaba, SP, v.13, n.1, p.7-36, mar. 2008.

MONTEIRO, Ana Maria. Ensino de história: lugar de fronteira. In: SIMPÓSIO NACIONAL DE HISTÓRIA, 24. 2007, Anpuh, Londrina. Anais eletrônicos... Disponível em: http://anpuh.org/anais/wp-content/uploads/ANPUH.S24.pdf; Acesso em: 25 mar. 2015.

Professores de História: entre saberes e práticas. Rio de Janeiro: Mauad, 2007.

NADAI, Elza. A prática de ensino e a democratização da escola. Revista da Faculdade de Educação, São Paulo: USP, v.11. n.1/2, p.5-17, jan./dez., 1985.

ROSSATO, Luciana et al. (Org.) Experiências de ensino de História no Estágio Supervisionado. v. II. Florianópolis: Ed. Udesc, 2012.

RÜSEN, Jörn. Didática da História: passado, presente e perspectivas a partir do caso alemão. Práxis Educativa, Ponta Grossa, v.1, n.2, p.7-16, jul./dez. 2006. Disponível em: www.revistas2.uepg.br/index.php/praxiseducativa/article/view/279/285; Acesso em: 4 abr. 2015.

História viva. Teoria da História III: formas e funções do conhecimento histórico. Brasília: Ed. UnB, 2007.

SCHMIDT, Maria Auxiliadora; BARCA, Isabel; MARTINS, Estevão de Rezende. Jörn Rüssen e o ensino de História. Curitiba: Ed. UFPR, 2010. 
SILVA, Cristiani Bereta da. Atualizando a Hidra? O estágio supervisionado e a formação docente inicial em História. Educação em Revista, v.26, n.1, p.131-156, 2010.

SILVA, Cristiani Bereta da et al. (Org.) Experiências de ensino de História no Estágio Supervisionado. Florianópolis: Ed. Udesc, 2011.

\section{NOTAS}

${ }^{1}$ Uma das autoras deste artigo, Rosiane Bechler, residiu entre 2007 e 2010 na cidade de Würzburg, Alemanha. Nesse período ela trabalhou como professora voluntária na Escola Especial Leo-Deeg, e entre 2007 e 2009, com a professora regente Gudrun Freifrau von Wiedersperg.

${ }^{2}$ Informações disponíveis em: www.km.bayern.de/lehrer/lehrerausbildung.html; Acesso em: 27 mar. 2015.

${ }^{3}$ Endereço eletrônico: www.uni-wuerzburg.de/startseite/.

${ }^{4}$ Disponível em: www.tutoria.de/schule-ratgeber/schulsysteme/schulsystem-bayern; Acesso em: 1 abr. 2015. Observação: registramos a tradução livre das denominações em alemão.

${ }^{5}$ Além de sua característica dual, o sistema de ensino alemão também conta com escolas especiais, denominadas Sonderschule, voltadas para alunos com deficiências físicas, psíquicas e cognitivas.

${ }^{6}$ Caso optem e estejam aptos, os alunos da Escola Média podem prosseguir seus estudos por mais um ano e inscreverem-se para o exame de conclusão do ensino médio equivalente ao conferido pela Escola Real, Realschule.

${ }^{7}$ A título de exemplo, citamos os cursos de Engenharia e Enfermagem que, na Alemanha, são considerados cursos técnicos.

${ }^{8}$ Assim como juristas e médicos, na Alemanha também os professores têm sua licença para atuar condicionada à aprovação em dois exames estatais; um ao fim da primeira fase da formação, Studium, e outro ao fim da segunda, Refendariat.

${ }^{9} \mathrm{O}$ que se convencionou chamar de "Processo de Bolonha" iniciou-se como uma declaração conjunta de ministros da Educação europeus assinada na cidade de Bolonha (Itália) em 19 de junho de 1999. O documento assinala acordo de uma política pública educacional supranacional, comum aos Estados-membros da União Europeia, com o objetivo de construir um "espaço europeu de educação superior". O processo político, que redundou em reformas institucionais, tem como meta construir um novo sistema europeu de educação superior que seja comum aos Estados-membros da União Europeia. Informações disponíveis em: http://europa.eu/legislation_summaries/education_training_youth/lifelong_ learning/c11088_pt.htm; Acesso em: 29 mar. 2015. Ver também: LIMA; AZEVEDO; CATANI, 2008. 
${ }^{10}$ Um crédito ou ECT-PUNKTE corresponde a cerca de 25/30 horas de trabalho dos estudantes.

${ }^{11}$ Disponível em: www.geschichte.uni-wuerzburg.de/studium/; Acesso em: 1 abr. 2015.

${ }^{12}$ Idem.

${ }^{13}$ Caso o estudante já tenha tido uma outra experiência de trabalho, pode solicitar ao setor de estágios da Universidade que a reconheça como o estágio requerido.

${ }^{14}$ Lehramt na Realschulen. Disponível em: www.uni-wuerzburg.de/fuer/studierende/angebot/abschluss/stex/la_rs/; Acesso em: 1 abr. 2015.

${ }^{15}$ Idem.

${ }^{16}$ No $1^{\circ}$ ano do Refendariat os professorandos também são remunerados, mas nessa segunda etapa o salário tem uma equiparação maior com o dos professores em atuação.

${ }^{17} \mathrm{O}$ estado da Bavária publica anualmente um prognóstico acerca da demanda por professores no estado. O documento de 2015 pode ser acessado em: www.km.bayern.de/epaper/ Lehrerbedarfsprognose_2015_Hauptveroeffentlichung/files/assets/common/downloads/ publication.pdf.

${ }^{18}$ Sobre o assunto ver: SCHIMIDT; BARCA; MARTINS, 2010; CERRI, 2011.

${ }^{19}$ Informações disponíveis em: www.faed.udesc.br/arquivos/id_submenu/1164/plano_de_ curso_licenciatura.pdf; Acesso em: 3 abr. 2015.

${ }^{20}$ Essa disciplina tem pré-requisitos. Para se matricular nela o aluno precisa ter cursado todas as disciplinas do $1^{\circ}$ ao $4^{\circ}$ semestre do curso. A Udesc possui funcionamento semestral e disciplinar, assim optamos - mesmo reconhecendo certo enrijecimento do percurso - por manter os pré-requisitos após a reforma curricular. Isso porque entendemos que os estudantes estão entrando no curso cada vez mais jovens (17, 18 anos) e esse tempo é o mínimo necessário para eles - ao menos - se ambientarem com a proposta do curso. Ver matriz curricular em: www.faed.udesc.br/arquivos/id_submenu/1134/matriz_curricular_ licenciatura.pdf; Acesso em: 25 mar. 2015.

${ }^{21}$ É o professor da disciplina de estágio, também nomeado como professor orientador, quem organiza previamente e partir do perfil da turma, qual escola e turmas (Ensino Fundamental ou Médio) receberão esses grupos. Além das escolas estaduais e municipais há mais de 15 anos também o Colégio de Aplicação da Universidade Federal de Santa Catarina (UFSC) é campo de estágio do Curso de História da Udesc. Importante informar que além da carga horária da disciplina, o professor de Estágio Supervisionado pode alocar até 2 horas de orientação por aluno, em seu plano de atividades docentes. Em razão dessa carga horária de orientação cada professor não pode ter mais que 12 alunos numa turma de estágio. Ao contrário de outras experiências, na Udesc, as turmas não se duplicam, duplicam-se os docentes na turma e estes trabalham em conjunto, fazendo apenas as orientações e o acompanhamento nas escolas, de modo individual. As turmas são pequenas e normalmente trabalham dois professores por turma. Atualmente existem três professoras efetivas lotadas no Departamento de História que trabalham especificamente com Estágio 
Supervisionado: Cristiani Bereta da Silva, Luciana Rossato e Nucia Alexandra Silva de Oliveira.

${ }^{22} \mathrm{O}$ trabalho realizado nas escolas valoriza e privilegia o papel do professor da escola no processo de formação dos futuros professores. O diálogo entre o professor da disciplina de estágio e o professor da escola e entre este e os estagiários é constante nesse projeto e ganhou em qualidade após o início de projetos do Pibid nas escolas públicas.

${ }^{23}$ Alguns desses artigos escritos pelos estudantes do curso foram publicados em livros numa coleção criada pelo Laboratório de Ensino de História (LEH) chamada "Experiências de ensino de História no estágio supervisionado". Já foram publicados dois volumes, e um terceiro está sendo organizado para publicação ainda em 2015. Ver: SILVA et al., 2011, e ROSSATO et al., 2012.

${ }^{24}$ Nenhum problema em realizar estágios em turmas de Educação de Jovens e Adultos, mas há dificuldades pedagógicas e administrativas importantes, uma delas, por exemplo, refere-se ao fato de que as trocas de docentes são muito mais frequentes nessa modalidade, e é comum não haver um professor de História da EJA que possa também acompanhar os estudantes e mesmo mediar propostas pedagógicas relacionadas ao ensino de História que sejam mais adequadas ao perfil desses alunos.

${ }^{25}$ Apenas como medida de comparação, o Colégio de Aplicação da UFSC, espaço que também ocupamos para realizar nosso estágio, o Ensino Médio possui três aulas semanais de História de 45 minutos.

Artigo recebido em 14 de junho de 2015. Aprovado em 14 de julho de 2015. 